\title{
A Review of Extra-Terrestrial Mining Robot Concepts
}

Robert P. Mueller

Surface Systems Office, National Aeronautics \& Space Administration (NASA) Kennedy Space Center, FL, USA

Paul J. van Susante

Colorado School of Mines. Division OF Engineerong, Golden, CO. 8040, USA

\begin{abstract}
Outer space contains a vast amount of resources that offer virtually unlimited wealth to the humans that can access and use them for commercial purposes. One of the key technologies for harvesting these resources is robotic mining of regolith, minerals, ices and metals. The harsh environment and vast distances create challenges that are handled best by robotic machines working in collaboration with human explorers. Humans will benefit from the resources that will be mined by robots. They will visit outposts and mining camps as required for exploration, commerce and scientific research, but a continuous presence is most likely to be provided by robotic mining machines that are remotely controlled by humans.
\end{abstract}

There have been a variety of extra-terrestrial robotic mining concepts proposed over the last 100 years and this paper will attempt to summarize and review concepts in the public domain (government, industry and academia) to serve as an informational resource for future mining robot developers and operators. The challenges associated with these concepts will be discussed and feasibility will be assessed. Future needs associated with commercial efforts will also be investigated. 